\title{
Exposure to a single immobilization or lipopolysaccharide challenge increases expression of genes implicated in the development of Alzheimer's disease in the mice brain cortex
}

\author{
Alexandra Padova ${ }^{1,2}$, Ivana Rokytova ${ }^{1}$, Boris Mravec ${ }^{1,2}$, Richard Kvetnansky ${ }^{1}$, Peter Vargovic ${ }^{1}$ \\ ${ }^{1}$ Institute of Experimental Endocrinology, Biomedical Research Center, Slovak Academy of Sciences, Bratislava, Slovakia; \\ ${ }^{2}$ Institute of Physiology, Faculty of Medicine, Comenius University, Bratislava, Slovakia \\ E-mail:padova2@uniba.sk
}

Objectives. Despite extensive research efforts, mechanisms participating on development of Alzheimer's disease (AD) are covered only partially. Data from the last decades indicate that various stressors, as etiological factors, may play a role of in the AD. Therefore, we investigated the effect of two acute stressors, immobilization (IMO) and lipopolysaccharide (LPS), on the AD-related neuropathology.

Methods. Adult C57BL/6J mice males were exposed to a single IMO stress or a single intraperitoneal injection of LPS $(250 \mu \mathrm{g} / \mathrm{kg}$ body weight). After terminating the experiments, the brains were removed and their cortices isolated. Gene expression of pro-inflammatory cytokines, as well as expression of genes implicated in the $\mathrm{AD}$ neuropathology were determined. In addition, mediators related to the activation of the microglia, monocytes, and perivascular macrophages were determined in brain cortices, as well.

Results. In comparison with the control animals, we found increased gene expression of proinflammatory mediators in mice brain cortex in both IMO and LPS groups. In stressed animals, we also showed an increased expression of genes related to the $\mathrm{AD}$ neuropathology, as well as positive correlations between genes implicated in $\mathrm{AD}$ development and associated neuroinflammation.

Conclusions. Our data indicate that acute exposure to a strong IMO stressor, composed of the combined physical and psychological challenges, induces similar inflammatory and other ADrelated neuropathological changes as the immune LPS treatment. Our data also indicate that cytokines are most likely released from the peripheral immune cells, as we detected myeloid cells activity, without any microglia response. We hypothesize that stress induces innate immune response in the brain that consequently potentiate the expression of genes implicated in the AD-related neuropathology.

Key words: acute stress, amyloid precursor protein, immobilization, lipopolysaccharide, neuroinflammation

Alzheimer's disease is characterized by a progressive extracellular accumulation of amyloid $\beta$ peptides and intraneuronal accumulation of the hyperphosphorylated tau protein in the brain of the $\mathrm{AD}$ patients. Neuroinflammation represents another classical hallmark of the AD. The role of the neuroinflammation in the AD pathogenesis indicate findings of inflammatory reaction in the brain regions implicated in development of AD (cortex and hippocampus) (Akiyama et al. 2000; Shen et al. 2016).

Corresponding author: Alexandra Padova, Institute of Physiology, Faculty of Medicine, Comenius University, Sasinkova 2, 81372 Bratislava, Slovakia; phone: +421 259357 527; e-mail: padova2@uniba.sk. 
However, it is still a matter of debate whether neuroinflammation is the cause or only a consequence of the AD-related neuropathology. Several papers have indicated that subclinical neuroinflammation may be triggered by different factors that are implicated in the induction of the AD-related pathology, e.g. infection, toxic metabolites, brain injury, autoimmunity (Huang et al. 2017), and stress (Wohleb et al. 2014; Le et al. 2016; Piirainen et al. 2017).

Stress may induce AD-related neuropathology as well as neuroinflammation. Chronic stress may exacerbate amyloid $\beta$ pathology (Baglietto-Vargas et al. 2015). The production of toxic amyloid $\beta$ proteins in the brain parenchyma and brain vessels depends on the cleavage of the amyloid precursor protein (APP) by active domain of $\beta$-site APP cleaving enzyme 1 (BACE-1) in the cell membrane (Muller et al. 2017). High amyloid $\beta$ levels are associated with increased levels of hormones implicated in stress conditions (Green et al. 2006; Catania et al. 2009) and stress hormone antagonism might significantly prevent the onset of the cognitive impairment and amyloid $\beta$ aggregation in both the mice males and females without any toxicity (Zhang et al. 2016). In addition, stress-induced increase of the corticotropin-releasing hormone concentration in the brain can cause alterations in the phosphorylation of tau protein, and in turn affect the gene expression of tubulin $\beta 1$ (TUB $\beta 1$ ) and microtubule-associated protein tau (MAPT) in the brain (Rissman et al. 2007; Filipcik et al. 2012). The tau phosphorylation was thought to be a downstream event of the amyloid $\beta$ deposition. However, now, it is equally plausible that tau and amyloid $\beta$ act in a parallel manner in the enhancement of each other's toxic effects and initiate the pathogenic events leading to the development of AD (Small and Duff 2008; Spires-Jones and Hyman 2014). Finally, stress may modulate both central and peripheral inflammatory responses (Liu et al. 2017).

It has been suggested that AD-related neuropathology can by induced by a chronic stress. However, several findings have indicated that also acute exposure to stressors may play a role (Rissman et al. 2007; Krstic et al. 2012). To elucidate the role of the acute stress on the AD-related neuropathology, we exposed the mice either to a single IMO or LPS injection. In the brain cortex, we determined the expression of genes related to all three basic hallmarks of the AD: APP and BACE-1 implicated in amyloid $\beta$ pathology, TUB $\beta 1$ and MAPT implicated in tau pathology, and inflammatory markers (interleukin $1 \beta$ - IL- $1 \beta$, interleukin 6 - IL-6, tumor necrosis factor $\alpha-\mathrm{TNF} \alpha$ ). To elucidate the mechanisms responsible for the stress- induced neuroinflammation, we also determined several markers for the activity of the mononuclear cells (lymphocyte antigen 6 complex - LY6C, C-C chemokine receptor type 2 - CCR2, macrophage chemoattractant protein 1 - MCP1) and microglial activity (transforming growth factor $\beta 1$ - TGF $\beta 1$, triggering receptor expressed on myeloid cells 2 - TREM2, C-X3-C motif chemokine receptor 1 CX3CR1, cluster of differentiation 200 - CD200 and cluster of differentiation 200 receptor - CD200R).

\section{Material and methods}

Animals. Experiments were performed on 3-months old C57BL/6J male mice. Animals were housed 3-4 per cage and kept under controlled conditions in the animal facility of the Institute of Experimental Endocrinology (12 h light/12 h dark cycle, lights on at $06: 00 \mathrm{~h}$; temperature $22 \pm 1^{\circ} \mathrm{C}$, humidity $55 \pm 10 \%$ ) with free access to tap water and standard pelleted chow. All experiments were performed between 09:00 and 11:00 h. All experimental procedures were approved by the Animal Care Committee of the Institute of Experimental Endocrinology, Slovak Academy of Sciences, Bratislava, Slovakia and State Veterinary and Food Administration of the Slovak Republic (Approval No. Ro-3400/13-221). The mice received care in compliance with the Guide for the Care and Use of Laboratory Animals published by the U.S. National Institutes of Health.

Experimental protocol. Mice were randomly divided into three groups: a) CON - control mice strictly avoided of all the stress stimuli $(n=7)$; b) IMO - mice exposed to $2 \mathrm{~h}$ immobilization $(\mathrm{n}=6)$; and $\mathrm{c}$ ) LPS - mice intraperitoneally (i.p.) injected with LPS ( $250 \mu \mathrm{g} / \mathrm{kg}$ body weight) $(\mathrm{n}=6)$.

IMO group of animals was exposed to a single IMO for $2 \mathrm{~h}$ (Kvetnansky and Mikulaj 1970) and decapitated immediately after the termination of stressor exposure. LPS group of animals was i.p. injected by a single dose of LPS $250 \mu \mathrm{g} / \mathrm{kg}$ b.w. and decapitated 4 $\mathrm{h}$ after the LPS treatment, when the effect of LPS on immune system reaches the peak (White et al. 2017).

Tissue sampling. Immediately after decapitation, the brains were removed and their cortices isolated. Then, the cortices samples of the brain were cooled in the liquid nitrogen and stored at $-70^{\circ} \mathrm{C}$ until used for analysis. The left cortical hemispheres were used for gene expression analyses.

RNA isolation, reverse transcription and Real Time PCR. Total RNA was isolated using the TRI ReagentVR RT (MRC, Inc., Cincinnati, OH) according to the manufacturer's protocol and concen- 
Table 1

Table of primers

\begin{tabular}{|c|c|c|}
\hline Primer & & Sequence \\
\hline \multirow{2}{*}{ TBP } & For & 5'-GGCGGTTTGGCTAGGTTT-3' \\
\hline & Rev & 5'-GGGTTATCTTCACACACCATGA-3' \\
\hline \multirow{2}{*}{ IL-1 $\beta$} & For & $5^{\prime}$-AGTTGACGGACCCCAAAAG-3' \\
\hline & Rev & 5'-AGCTGGATGCTCTCATCAGG-3' \\
\hline \multirow{2}{*}{ IL-6 } & For & 5'-CTCTGCAAGAGACTTCCATCCAGT-3' \\
\hline & Rev & 5'-AGACAGGTCTGTTGGGAGTGGT-3' \\
\hline \multirow{2}{*}{ TNF $\alpha$} & For & 5'-GATCGGTCCCCAAAGGGATG-3' \\
\hline & Rev & 5'-CCACTTGGTGGTTTGTGAGTG-3' \\
\hline \multirow{2}{*}{ APP } & For & $5^{\prime}$-AGGACTGACCACTCGACCAG-3' \\
\hline & Rev & 5'-CTTCCGAGATCTCTTCCGTCT-3' \\
\hline \multirow{2}{*}{ BACE1 } & For & 5'-CGACCACTCGCTATACACGG-3' \\
\hline & $\operatorname{Rev}$ & 5'-GGAACTTCTCCGTCTCCTTGC-3' \\
\hline \multirow{2}{*}{ MAPT } & For & 5'-GATGATGGAGCGGAGGAACC-3' \\
\hline & $\operatorname{Rev}$ & 5'-TCCTTCTGGGATCTCCGTGT-3' \\
\hline \multirow{2}{*}{ TUB $\beta 1$} & For & 5'-CTGTGGGACGTCTGCTCTC-3' \\
\hline & Rev & 5'-GCGGCACATACTTCTTACCG-3' \\
\hline \multirow{2}{*}{ LY6C } & For & 5'-ATCTGTGCAGCCCTTCTCTG-3' \\
\hline & Rev & 5'-TCCСTGAGCTCTTTCTGCAC-3' \\
\hline \multirow{2}{*}{ CCR2 } & For & 5'-AGGAGCCATACCTGTAAATGC-3' \\
\hline & Rev & 5'-ATGCCGTGGATGAACTGAGG-3' \\
\hline \multirow{2}{*}{ MCP1 } & For & 5'-CCACAACCACCTCAAGCACT-3' \\
\hline & Rev & 5'-AGGCATCACAGTCCGAGTCA-3' \\
\hline \multirow{2}{*}{ TGF $\beta 1$} & For & 5'-TGGAGCAACATGTGGAACTC-3' \\
\hline & Rev & 5'-GTCAGCAGCAGTTTACCA-3' \\
\hline \multirow{2}{*}{ TREM2 } & For & 5'-CCTCCAGGCAGGTTTCATCC-3' \\
\hline & $\operatorname{Rev}$ & 5'-GGTGGGAAGGAGGTCTCTTG-3' \\
\hline \multirow{2}{*}{ CX3CR1 } & For & 5'-AAGTTCCCTTCCCATCTGCT-3' \\
\hline & Rev & 5'-CAAAATTCTCTAGATCCAGTTCAGG-3 \\
\hline \multirow{2}{*}{ CD200 } & For & 5'-GGCAGTCTGGTATTCAGGAGAC-3' \\
\hline & Rev & 5'-GCGCCTTTCTTTCATCCTGG-3' \\
\hline \multirow{2}{*}{ CD200R } & For & 5'-ATGTGTCTGATGTGTCTTGCAT-3' \\
\hline & Rev & 5'-TTGCATTTTCTGAAGCCACTGA-3' \\
\hline
\end{tabular}

trations were quantified using the NanoDrop 2000 (Thermo Fisher Scientific, Waltham, MA). Reverse transcription of RNA (1500 ng from brain region tissue) was performed with the Illustra Ready-To$\mathrm{Go}^{\mathrm{m}}$ RT-PCR Beads (GE Healthcare, UK), according to the manufacturers' protocol. Semi-quantitative Real-Time PCR was set up in a total volume of $10 \mu \mathrm{l}$ containing $500 \mathrm{ng}$ of template cDNA mixed with $5 \mu$ of SensiFast ${ }^{\text {te }}$ Sybr Hi-Rox Mix (Bioline, UK), $1 \mu \mathrm{l}$ of specific self-designed primer pair set (Micro- synth AG, Switzerland; sequences of used primers are shown in Table 1), and $2 \mu \mathrm{l}$ of water. Each sample was analyzed on an ABI7900HT Fast Real-Time PCR instrument (Applied Biosystems, Foster City, CA) under the following conditions: one cycle of $2 \mathrm{~min}$ at $50^{\circ} \mathrm{C}$, followed by one cycle of initial denaturation for $2 \mathrm{~min}$ at $95^{\circ} \mathrm{C}$ and then 40 cycles of denaturation $\left(95^{\circ} \mathrm{C}\right.$ for $\left.5 \mathrm{~s}\right)$ annealing and elongation $\left(60^{\circ} \mathrm{C}\right.$ for $20 \mathrm{~s}$ ). Data were obtained from software SDS 2.4 (Applied Biosystems, Foster City, CA) and normalized to TATA-binding protein (TBP) mRNA levels. Relative fold change was calculated using the $\Delta \Delta \mathrm{Ct}$ method (Schmittgen and Livak 2008).

Statistical analysis. Results were evaluated by Student $t$-test and expressed as the mean \pm SEM. Linear regression and Pearson's correlation coefficient were used to measure the statistical relationship, or association, between two continuous variables. Statistical analysis was performed using GraphPad Prism 8. Differences were considered statistically significant at $\mathrm{p}<0.05$. Data are expressed as mean \pm SEM and representing the mean for 6-7 mice.

\section{Results}

Comparing to CON (unstressed) animals, we found significantly increased gene expression of IL-1 $\beta$ (IMO $p=0.0092$; and LPS $p=0.0011$ ), IL-6 (IMO $\mathrm{p}<0.0001 ;$ LPS $\mathrm{p}=0.0031), \mathrm{TNF} \alpha(\mathrm{IMO} \mathrm{p}=0.0404 ;$ LPS $\mathrm{p}=0.0001)$ in the cortex of both experimental groups exposed to stressors (Figure 1).

LPS challenge significantly increased the expression of four genes implicated in AD-related neuropathology: APP $(\mathrm{p}=0.0086)$, BACE-1 $(\mathrm{p}=0.0056)$, TUB $\beta 1 \quad(p=0.0007)$ and MAPT $(\mathrm{p}=0.0184)$. IMO significantly increased the gene expression of APP $(\mathrm{p}=0.0463)$ and TUB $\beta 1 \quad(\mathrm{p}=0.0447)$ (Figure 2). The linear regression revealed significant correlation between the levels of mRNA of APP and MAPT (IMO $\mathrm{p}=0.0261$; LPS $\mathrm{p}=0.0412$ ), APP and TUB $\beta 1$ (IMO $\mathrm{p}=0.0003$; LPS $\mathrm{p}=0.0002$ ), APP and IL-6 (IMO $\mathrm{p}=0.0018)$ and APP and TNFa (IMO $\mathrm{p}=0.0261$; LPS $\mathrm{p}=0.0046$ ) in the mice cortex (Figure 3).

To elucidate the mechanisms responsible for the stress-induced inflammatory response, we determined gene expression of markers for the mononuclear cells (LY6C, CCR2, and MCP1). We found increased gene expression of LY6C in cortex of both stressed groups (IMO $\mathrm{p}=0.0493$; LPS $\mathrm{p}<0.0001$ ). Additionally, immobilized mice showed increased MCP1 mRNA ( $\mathrm{p}=0.0224)$, whereas LPS-treated group showed increased gene expression of its receptor CCR2 ( $\mathrm{p}=0.0052)$ (Figure 4). 


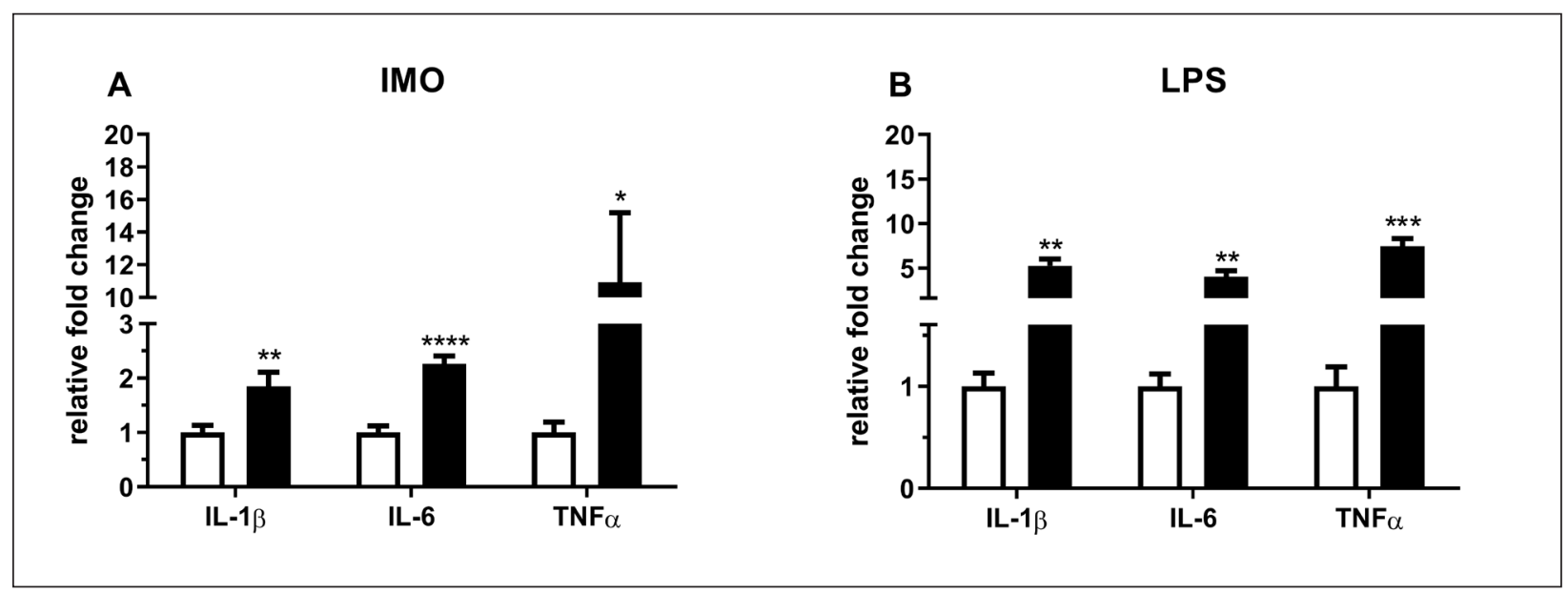

Figure 1. Gene expression of pro-inflammatory mediators in IMO exposed group (A) and LPS-treated group (B). Mice were exposed to $2 \mathrm{~h}$ IMO or injected with $250 \mu \mathrm{g} / \mathrm{kg}$ b.w. LPS (white column - control group, $\mathrm{n}=7$; black column - experimental treated groups, $n=6$ ). Each value represents the mean \pm SEM. The level of statistical significance ${ }^{\star} \mathrm{p}<0.05,{ }^{* *} \mathrm{p}<0.01,{ }^{* * *} \mathrm{p}<0.001,{ }^{* * *} \mathrm{p}<0.0001$ determines significant differences between control vs. experimental group. Abbreviations: IMO - immobilization; LPS - lipopolysaccharide; b.w. - body weight.

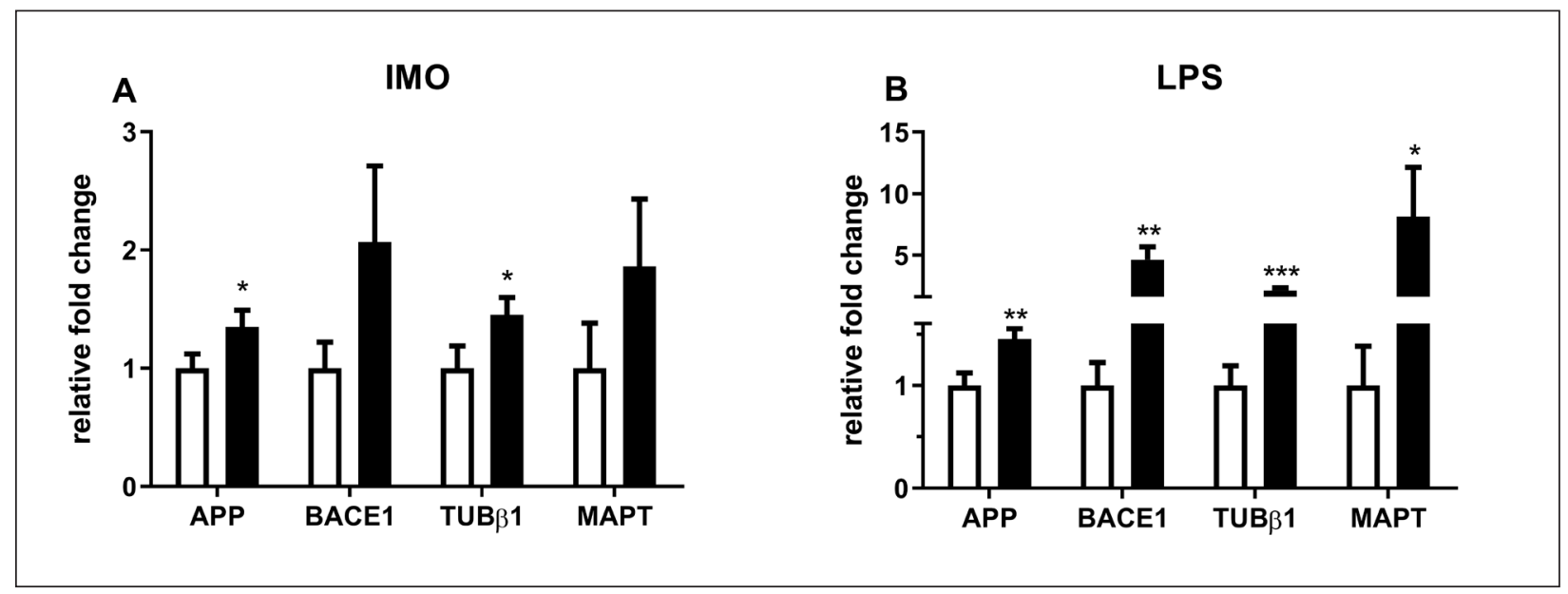

Figure 2. Expression of genes implicated in development of AD pathology in IMO exposed group (A) and LPStreated group (B). Mice were exposed to $2 \mathrm{~h} \mathrm{IMO}$ or injected with $250 \mu \mathrm{g} / \mathrm{kg}$ b.w. LPS (white column - control group, $n=7$; black column - experimental treated groups, both $n=6$ ). Each value represents the mean \pm SEM. The level of statistical significance ${ }^{\star} \mathrm{p}<0.05,{ }^{* *} \mathrm{p}<0.01,{ }^{\star * *} \mathrm{p}<0.001,{ }^{* * *} \mathrm{p}<0.0001$ determines significant differences between control vs. experimental group. Abbreviations: AD - Alzheimer's disease; IMO - immobilization; LPS - lipopolysaccharide; b.w. - body weight.

To elucidate the cell type triggering LPS/IMOevoked inflammatory response, factors activating or inhibiting of activity of microglia, gene expression of TGF $\beta 1$, TREM2, CX3CR1, CD200, and CD200R was determined. However, gene expression of these factors did not show any significant changes in stressed animals (Figure 5).

\section{Discussion}

The role of the stress as well as the pathways and mechanisms responsible for the stress-induced AD-related neuropathology still remains a matter of the debate. It has been shown that single restraint stress is sufficient to elevate the expression of inflam- 


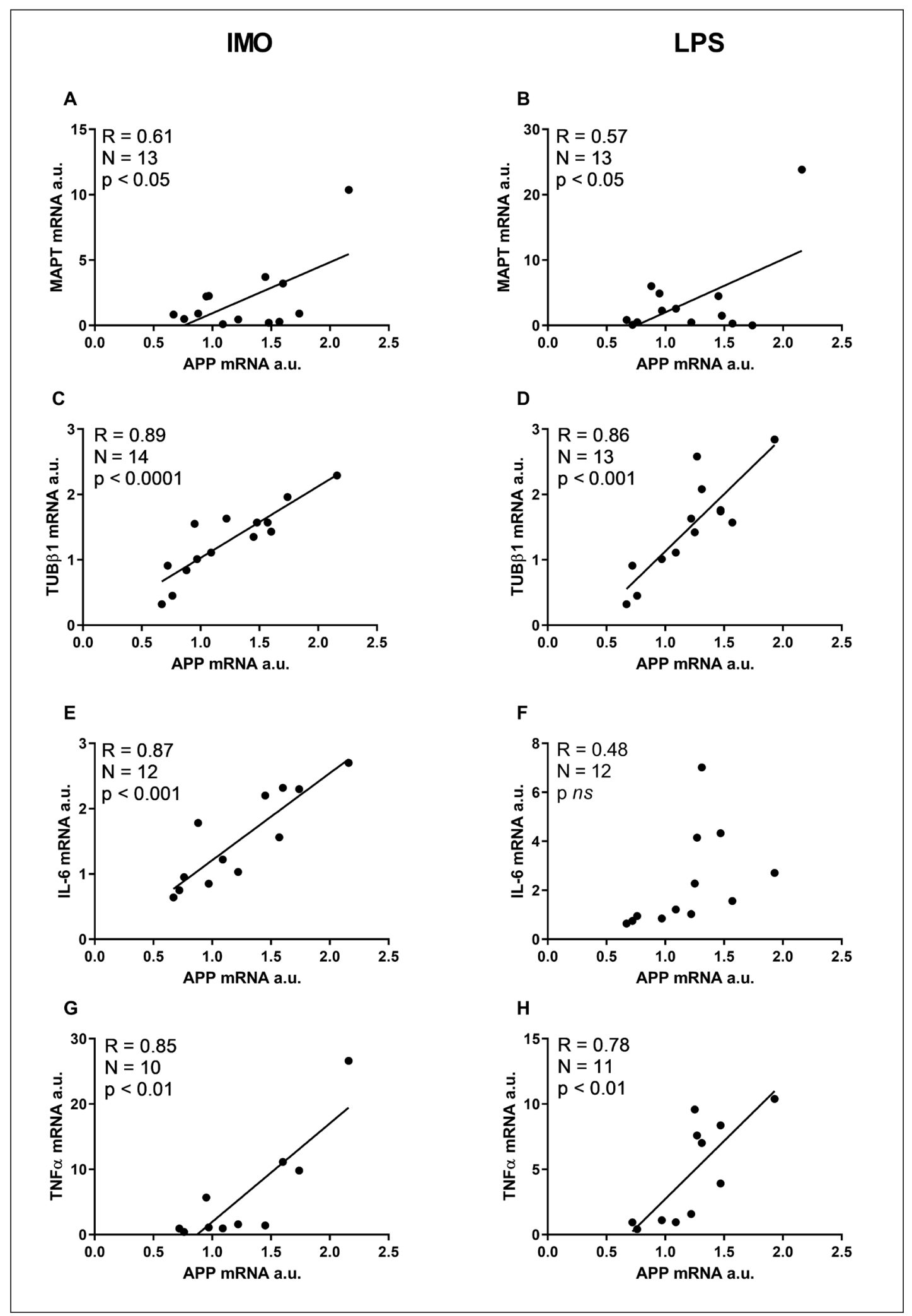

Figure 3. Correlations of APP mRNA in IMO exposed group (A, C, E, G) and LPS-treated group (B, D, F, H). Mice were exposed to $2 \mathrm{~h} \mathrm{IMO}$ or injected with $250 \mu \mathrm{g} / \mathrm{kg}$ b.w. LPS. Abbreviations: APP - amyloid precursor protein; IMO - immobilization; LPS - lipopolysaccharide; b.w. - body weight. 


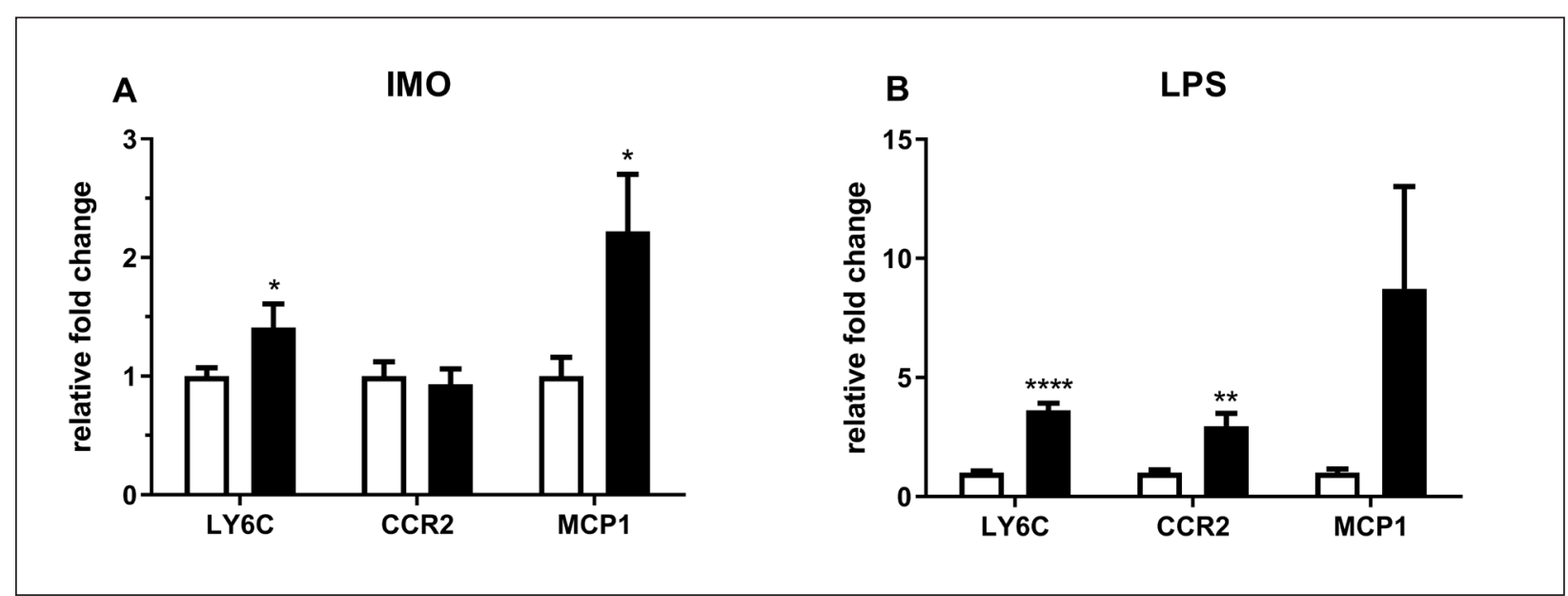

Figure 4. Expression of mononuclear cell markers in IMO exposed group (A) and LPS-treated group (B). Mice were exposed to $2 \mathrm{~h}$ IMO or injected with $250 \mu \mathrm{g} / \mathrm{kg}$ b.w. LPS (white column - control group, n=7; black column - experimental treated groups, both $\mathrm{n}=6$ ). Each value represents the mean \pm SEM. The level of statistical significance ${ }^{*} \mathrm{p}<0.05,{ }^{* *} \mathrm{p}<0.01,{ }^{* *} \mathrm{p}<0.001,{ }^{* * *} \mathrm{p}<0.0001$ determines significant differences between control vs. experimental group. Abbreviations: IMO - immobilization, LPS - lipopolysaccharide; b.w. - body weight.

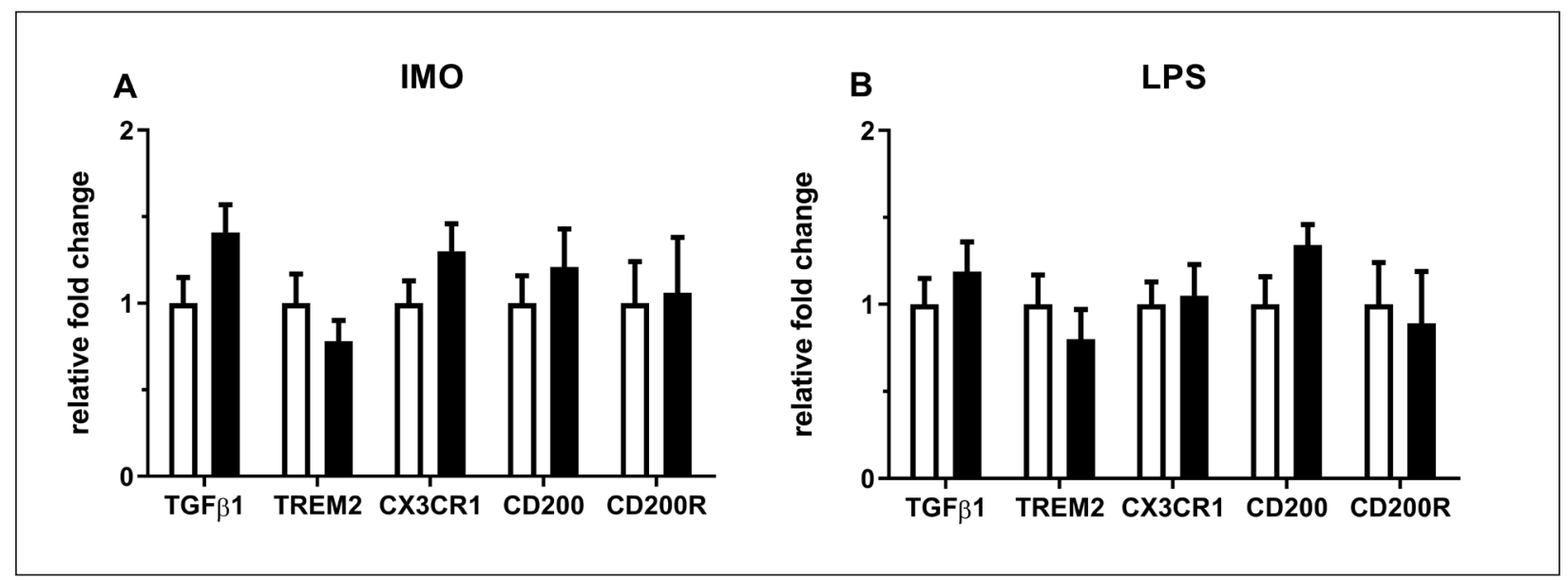

Figure 5. Gene expression of microglial modulators in IMO exposed group (A) and LPS-treated group (B). Mice were exposed to $2 \mathrm{~h}$ IMO or injected with $250 \mu \mathrm{g} / \mathrm{kg}$ b.w. LPS (white column - control group, n=7; black column - experimental treated groups, both $\mathrm{n}=6$ ). Each value represents the mean \pm SEM. The level of statistical significance ${ }^{*} \mathrm{p}<0.05,{ }^{* *} \mathrm{p}<0.01,{ }^{* *} \mathrm{p}<0.001,{ }^{* * *} \mathrm{p}<0.0001$ determines significant differences between control vs. experimental group. Abbreviations: IMO - immobilization, LPS - lipopolysaccharide; b.w. - body weight.

mation-related genes in the hippocampus in both $\mathrm{BABLB} / \mathrm{c}$ and C57BL/6 mice (Sathyanesan et al. 2017). In accordance with these studies, we hypothesize that the mechanisms of stress-induced AD-related changes may be evoked by the same effect as the immune challenge.

We showed that LPS challenge can induce increase in the expression of APP, BACE-1, MAPT and TUB $\beta 1$ genes, implicated in the development of AD-related neuropathology, whereas IMO the expression of APP and TUB $\beta 1$ genes, in the mice cortex (Figure 2). We found that increase of APP gene expression correlates with the increased gene expression of TUB $\beta 1$ and MAPT in both stressed groups (Figure 3) and was followed by an increase in the inflammatory cytokines IL- $1 \beta$, IL- 6 , and 
$\mathrm{TNFa}$, in the mice cortex (Figure 1). Importantly, TNF- $\alpha$ has been shown to stimulate the expression of APP and BACE-1 in the primary cultures of the mouse astrocytes (Zhao et al. 2011). In addition, it has been demonstrated that IL- 6 may potentiate the synthesis of the APP in neuronal human cells (Ringheim et al. 1998), and conversely, IL-6 is upregulated in cultured rat glial cells upon stimulation with the carboxy-terminal 105 amino acids of APP (Chong 1997). Our results are in accordance with studies proposing that systemic inflammation acts as a potent inducer of the AD-associated changes concerning the amyloid $\beta$ and tau protein synthesis/modifications. It has been documented that experimental brain injury can induce expression of APP, which may be related to the neuronal loss in the hippocampus (Murakami et al. 1998) and that neurocognitive deficits in the hippocampus of middle aged rodents are linked to the intraperitoneal administration of the bacterial LPS (Liu et al. 2012). More recent study has revealed an association between the $\mathrm{AD}$ development and the traumatic brain injury in humans (Marklund et al. 2014).

The importance of inflammatory pathways for the pathogenesis of $\mathrm{AD}$ is highlighted by the results of the genome-wide associated studies (GWAS), which indicate that many of the implicated genes play an important role in the immunological processes that regulate the phagocytosis and the activation state of the microglia/macrophages (Moraes et al. 2012). It has been shown that microglia loses of its amyloid $\beta$ clearing capabilities as the $\mathrm{AD}$ progresses (Lai and McLaurin 2012). Microglial activity can be modulated by an active transport of cytokines and chemokines through the blood-brain barrier (Block et al. 2007) or passive transport of interleukins via the circumventricular organs (Nakano et al. 2015). However, in our experimental model, there were no significant changes seen in the gene expression of markers studied indicating for the brain immune activity by neuronal CD200 and its microglial receptor CD200R (Yi et al. 2012), or suppression of inflammatory cytokines release from microglia mediated by TREM2 (Mecca et al. 2018) (Figure 5). Restricted expression of the chemokine receptor CX3CR1 in microglia (Wolf et al. 2013), as one of the stress-responsive gene involved in neuroinflammation accompanying neurodegenerative tau pathology, has been described in rats (Novak et al. 2018). But we did not observe any changes in the expression of CX3CR1 in mice cortex indicating for a quiescent "sampling" or surveillance mode of microglia as it has previously been reviewed (Biber et al. 2007). Taken together, our data indicate that microglia in the brain of stressed mice are in resting phase that can be similar to the microglial senescence in the AD patients (Guerriero et al. 2017). We suggest that inflammatory response manifested by an increased expression of IL-1 $\beta$, IL- 6, TNFa and LY6C genes (Figure 1, Figure 4) in mice cortex is most likely mediated by activation of other immune cells, e.g. astrocytes, endothelial cells, perivascular macrophages, and/or peripheral monocytes within the blood-brain barrier (Erta et al. 2012).

Important reactions of the perivascular perimeningeal macrophages and vascular endothelial cells can be triggered in the brain-periphery communication loop. It is likely that LPS-induced peripheral inflammation may cause neuroinflammatory reaction in the cortex via MCP1/CCR2 pathway, what can lead to an apoptosis (Bidzhekov et al. 2006; Zhou et al. 2006). It is interesting that the IMO induces the same effect (Sathyanesan et al. 2017). We found an increase of MCP1 gene expression without any changes in the gene expression of its receptor CCR2 in the cortex of IMO mice (Figure 4). Important role of MCP1 in $\mathrm{AD}$ pathology is supported by the evidence that MCP1 can enhance microglial amyloid $\beta$ degradation, both in vivo and in vitro conditions. On the contrary, chronic expression of MCP1 has adverse effects on the amyloid $\beta$ deposition (Yamamoto et al. 2005, 2007). Furthermore, elevated gene expression of CCR2 in LPS-treated group was observed simultaneously with the enhanced APP and TNF $\alpha$ mRNA production in the mice cortex. We hypothesize that increased gene expression of CCR2 during systemic inflammation might represent the first potent apoptotic signal in the LPS-induced neurodegenerative processes. Stimulation of MCP1/CCR2 apoptotic pathway has been shown to be driven by high levels of IL-6 and its receptor in the cell cultures (Modur et al. 1997) and mice (Romano et al. 1997), which is comparable with the elevated IL-6 mRNA in IMO/ LPS groups.

\section{Conclusions}

We found that a single exposure to either IMO or LPS can elevate the gene expression of factors related to all three hallmarks of the $\mathrm{AD}$, i.e. amyloid $\beta$ and tau pathology and neuroinflammation. Our data indicate that both the stressors used may induce peripheral inflammation with consequent induction of neuroinflammation as well as other AD-related neuropathological changes. Importantly, we showed that even a single exposure to strong stressor is able to 
induce significant changes related to the AD-related neuropathology. Therefore, it can by hypothesized that repeated exposure to strong stressors (psychological, biological, and others) may have a cumulative effect, which may compromise the cellular and tissue homeostasis and thus participated on development of the AD.

\section{Acknowledgments}

This work was supported by the Slovak Research and Development Agency No. APVV-0088-10, VEGA grant No. 2/0069/18, and European Regional Development Fund Research and Development Grant (ITMS 26240120015).

\section{References}

Akiyama H, Barger S, Barnum S, Bradt B, Bauer J, Cole GM, Cooper NR, Eikelenboom P, Emmerling M, Fiebich BL, Finch CE, Frautschy S, Griffin WS, Hampel H, Hull M, Landreth G, Lue L, Mrak R, Mackenzie IR, McGeer PL, O’Banion MK, Pachter J, Pasinetti G, Plata-Salaman C, Rogers J, Rydel R, Shen Y, Streit W, Strohmeyer R, Tooyoma I, Van Muiswinkel FL, Veerhuis R, Walker D, Webster S, Wegrzyniak B, Wenk G, Wyss-Coray T. Inflammation and Alzheimer's disease. Neurobiol Aging 21, 383-421, 2000.

Baglietto-Vargas D, Chen Y, Suh D, Ager RR, Rodriguez-Ortiz CJ, Medeiros R, Myczek K, Green KN, Baram TZ, LaFerla FM. Short-term modern life-like stress exacerbates Abeta-pathology and synapse loss in 3xTg-AD mice. J Neurochem 134, 915-926, 2015.

Biber K, Neumann H, Inoue K, Boddeke HW. Neuronal 'On' and 'Off' signals control microglia. Trends Neurosci 30, 596-602, 2007.

Bidzhekov K, Zernecke A, Weber C. MCP-1 induces a novel transcription factor with proapoptotic activity. Circ Res 98, 1107-1109, 2006.

Block ML, Zecca L, Hong JS. Microglia-mediated neurotoxicity: uncovering the molecular mechanisms. Nat Rev Neurosci 8, 57-69, 2007.

Catania C, Sotiropoulos I, Silva R, Onofri C, Breen KC, Sousa N, Almeida OF. The amyloidogenic potential and behavioral correlates of stress. Mol Psychiatry 14, 95-105, 2009.

Erta M, Quintana A, Hidalgo J. Interleukin-6, a major cytokine in the central nervous system. Int J Biol Sci 8, 12541266, 2012.

Filipcik P, Novak P, Mravec B, Ondicova K, Krajciova G, Novak M, Kvetnansky R. Tau protein phosphorylation in diverse brain areas of normal and CRH deficient mice: up-regulation by stress. Cell Mol Neurobiol 32, 837-845, 2012.

Green KN, Billings LM, Roozendaal B, McGaugh JL, LaFerla FM. Glucocorticoids increase amyloid-beta and tau pathology in a mouse model of Alzheimer's disease. J Neurosci 26, 9047-9056, 2006.

Guerriero F, Sgarlata C, Francis M, Maurizi N, Faragli A, Perna S, Rondanelli M, Rollone M, Ricevuti G. Neuroinflammation, immune system and Alzheimer disease: searching for the missing link. Aging Clin Exp Res 29, 821-831, 2017.

Huang NQ, Jin H, Zhou SY, Shi JS, Jin F. TLR4 is a link between diabetes and Alzheimer's disease. Behav Brain Res 316, 234-244, 2017.

Chong Y. Effect of a carboxy-terminal fragment of the Alzheimer's amyloid precursor protein on expression of proinflammatory cytokines in rat glial cells. Life Sci 61, 2323-2333, 1997.

Krstic D, Madhusudan A, Doehner J, Vogel P, Notter T, Imhof C, Manalastas A, Hilfiker M, Pfister S, Schwerdel C, Riether C, Meyer U, Knuesel I. Systemic immune challenges trigger and drive Alzheimer-like neuropathology in mice. J Neuroinflammation 9, 151, 2012.

Kvetnansky R, Mikulaj L. Adrenal and urinary catecholamines in rats during adaptation to repeated immobilization stress. Endocrinology 87, 738-743, 1970.

Lai AY, McLaurin J. Clearance of amyloid-beta peptides by microglia and macrophages: the issue of what, when and where. Future Neurol 7, 165-176, 2012.

Le MH, Weissmiller AM, Monte L, Lin PH, Hexom TC, Natera O, Wu C, Rissman RA. Functional impact of corticotropin-releasing factor exposure on Tau phosphorylation and axon transport. PLoS One 11, e0147250, 2016.

Liu X, Wu Z, Hayashi Y, Nakanishi H. Age-dependent neuroinflammatory responses and deficits in long-term potentiation in the hippocampus during systemic inflammation. Neuroscience 216, 133-142, 2012.

Liu YZ, Wang YX, Jiang CL. Inflammation: The common pathway of stress-related diseases. Front Hum Neurosci 11, 316, 2017. 
Marklund N, Farrokhnia N, Hanell A, Vanmechelen E, Enblad P, Zetterberg H, Blennow K, Hillered L. Monitoring of beta-amyloid dynamics after human traumatic brain injury. J Neurotrauma 31, 42-55, 2014.

Mecca C, Giambanco I, Donato R, Arcuri C. Microglia and aging: the role of the TREM2-DAP12 and CX3CL1CX3CR1 axes. Int J Mol Sci 19, 318, 2018.

Modur V, Li Y, Zimmerman GA, Prescott SM, McIntyre TM. Retrograde inflammatory signaling from neutrophils to endothelial cells by soluble interleukin-6 receptor alpha. J Clin Invest 100, 2752-2756, 1997.

Moraes CF, Lins TC, Carmargos EF, Naves JO, Pereira RW, Nobrega OT. Lessons from genome-wide association studies findings in Alzheimer's disease. Psychogeriatrics 12, 62-73, 2012.

Muller UC, Deller T, Korte M. Not just amyloid: physiological functions of the amyloid precursor protein family. Nat Rev Neurosci 18, 281-298, 2017.

Murakami N, Yamaki T, Iwamoto Y, Sakakibara T, Kobori N, Fushiki S, Ueda S. Experimental brain injury induces expression of amyloid precursor protein, which may be related to neuronal loss in the hippocampus. J Neurotrauma 15, 993-1003, 1998.

Nakano Y, Furube E, Morita S, Wanaka A, Nakashima T, Miyata S. Astrocytic TLR4 expression and LPS-induced nuclear translocation of STAT3 in the sensory circumventricular organs of adult mouse brain. J Neuroimmunol 278, 144-158, 2015.

Novak P, Cente M, Kosikova N, Augustin T, Kvetnansky R, Novak M, Filipcik P. Stress-induced alterations of immune profile in animals suffering by Tau protein-driven neurodegeneration. Cell Mol Neurobiol 38, 243-259, 2018.

Piirainen S, Youssef A, Song C, Kalueff AV, Landreth GE, Malm T, Tian L. Psychosocial stress on neuroinflammation and cognitive dysfunctions in Alzheimer's disease: the emerging role for microglia? Neurosci Biobehav Rev 77, 148-164, 2017.

Ringheim GE, Szczepanik AM, Petko W, Burgher KL, Zhu SZ, Chao CC. Enhancement of beta-amyloid precursor protein transcription and expression by the soluble interleukin- 6 receptor/interleukin- 6 complex. Brain Res Mol Brain Res 55, 35-44, 1998.

Rissman RA, Lee KF, Vale W, Sawchenko PE. Corticotropin-releasing factor receptors differentially regulate stressinduced tau phosphorylation. J Neurosci 27, 6552-6562, 2007.

Romano M, Sironi M, Toniatti C, Polentarutti N, Fruscella P, Ghezzi P, Faggioni R, Luini W, van Hinsbergh V, Sozzani S, Bussolino F, Poli V, Ciliberto G, Mantovani A. Role of IL-6 and its soluble receptor in induction of chemokines and leukocyte recruitment. Immunity 6, 315-325, 1997.

Sathyanesan M, Haiar JM, Watt MJ, Newton SS. Restraint stress differentially regulates inflammation and glutamate receptor gene expression in the hippocampus of C57BL/6 and BALB/c mice. Stress 20, 197-204, 2017.

Shen X, Chen J, Li J, Kofler J, Herrup K. Neurons in vulnerable regions of the Alzheimer's disease brain display reduced ATM signaling. eNeuro 3, ENEURO.0124-0115.2016, 2016.

Schmittgen TD, Livak KJ. Analyzing real-time PCR data by the comparative C(T) method. Nat Protoc 3, 1101-1108, 2008.

Small SA, Duff K. Linking Abeta and tau in late-onset Alzheimer's disease: a dual pathway hypothesis. Neuron 60, $534-542,2008$.

Spires-Jones TL, Hyman BT. The intersection of amyloid beta and tau at synapses in Alzheimer's disease. Neuron 82, 756-771, 2014

White JD, Peterman JL, Hardy A, Eimerbrink MJ, Paulhus KC, Thompson MA, Chumley MJ, Boehm GW. Prior exposure to repeated peripheral LPS injections prevents further accumulation of hippocampal beta-amyloid. Brain Behav Immun 66, e12-e13, 2017.

Wohleb ES, McKim DB, Sheridan JF, Godbout JP. Monocyte trafficking to the brain with stress and inflammation: a novel axis of immune-to-brain communication that influences mood and behavior. Front Neurosci 8, 447, 2014.

Wolf Y, Yona S, Kim KW, Jung S. Microglia, seen from the CX3CR1 angle. Front Cell Neurosci 7, 26, 2013.

Yamamoto M, Horiba M, Buescher JL, Huang D, Gendelman HE, Ransohoff RM, Ikezu T. Overexpression of monocyte chemotactic protein-1/CCL2 in beta-amyloid precursor protein transgenic mice show accelerated diffuse beta-amyloid deposition. Am J Pathol 166, 1475-1485, 2005.

Yamamoto M, Kiyota T, Walsh SM, Ikezu T. Kinetic analysis of aggregated amyloid-beta peptide clearance in adult bone-marrow-derived macrophages from APP and CCL2 transgenic mice. J Neuroimmune Pharmacol 2, 213-221, 2007.

Yi MH, Zhang E, Kang JW, Shin YN, Byun JY, Oh SH, Seo JH, Lee YH, Kim DW. Expression of CD200 in alternative activation of microglia following an excitotoxic lesion in the mouse hippocampus. Brain Res 1481, 90-96, 2012. 
Zhang C, Kuo CC, Moghadam SH, Monte L, Campbell SN, Rice KC, Sawchenko PE, Masliah E, Rissman RA. Corticotropin-releasing factor receptor-1 antagonism mitigates beta amyloid pathology and cognitive and synaptic deficits in a mouse model of Alzheimer's disease. Alzheimers Dement 12, 527-537, 2016.

Zhao J, O'Connor T, Vassar R. The contribution of activated astrocytes to Abeta production: implications for Alzheimer's disease pathogenesis. J Neuroinflammation 8, 150, 2011.

Zhou L, Azfer A, Niu J, Graham S, Choudhury M, Adamski FM, Younce C, Binkley PF, Kolattukudy PE. Monocyte chemoattractant protein-1 induces a novel transcription factor that causes cardiac myocyte apoptosis and ventricular dysfunction. Circ Res 98, 1177-1185, 2006. 